Activity Budgets and Foraging Ranges of Breeding Common Murres

Author(s): D. K. Cairns, K. A. Bredin and W. A. Montevecchi

Source: The Auk, Vol. 104, No. 2 (Apr., 1987), pp. 218-224

Published by: University of California Press on behalf of the American Ornithologists' Union

Stable URL: http://www.jstor.org/stable/4087027

Accessed: 30/05/2013 11:45

Your use of the JSTOR archive indicates your acceptance of the Terms \& Conditions of Use, available at http://www.jstor.org/page/info/about/policies/terms.jsp

JSTOR is a not-for-profit service that helps scholars, researchers, and students discover, use, and build upon a wide range of content in a trusted digital archive. We use information technology and tools to increase productivity and facilitate new forms of scholarship. For more information about JSTOR, please contact support@jstor.org. 


\title{
ACTIVITY BUDGETS AND FORAGING RANGES OF BREEDING COMMON MURRES
}

\author{
D. K. Cairns, K. A. BRedin, AND W. A. Montevecchi \\ Newfoundland Institute for Cold Ocean Science and Psychology Department, \\ Memorial University of Newfoundland, St. John's, Newfoundland A1C 3X9, Canada
}

\begin{abstract}
We used electronic activity recorders to measure flight time, dive time, and time on the water of breeding Common Murres (Uria aalge). During both incubation and chick rearing, about $90 \%$ of birds' time away from the colony was spent on the water or diving and $10 \%$ was spent flying. The proportion of flight time did not vary with trip duration. During chick rearing, $13.6 \%$ of time away from the colony was spent diving, and the proportion of time spent diving tended to decrease with trip duration. Potential foraging ranges calculated from flight times during individual foraging trips showed a concave frequency distribution, and median potential ranges were $37.8 \mathrm{~km}$ for incubating birds and 5.4 $\mathrm{km}$ for chick-rearing birds. The use of electronic recorders to measure time budgets has broad applications for seabird energetics and foraging ecology and for the assessment of prey availability and abundance. Received 21 April 1986, accepted 13 October 1986.
\end{abstract}

BECAUSE seabirds use energetically costly locomotion to search for food for themselves and their young, seabird activity budgets are important determinants of prey requirements and reproductive investment. Nevertheless, activities of seabirds at sea are among the least known aspects of their biology, and the scarcity of empirical activity data reduces the accuracy of seabird energetics models (e.g. Furness 1978, Furness and Cooper 1982, Gaston 1985) and limits our understanding of seabird foraging ecology (Ricklefs 1983, Wiens 1984).

Recently, Prince and Francis (1984) and Nagy et al. (1984) pioneered the use of nontransmitting activity recorders to directly measure time allocation by birds at sea. This approach seems more promising than the use of radiotelemetry because birds need not be close to the colony for data to be recorded (see Harrison 1981, Wanless et al. 1985). The devices used by Prince and Francis (1984) and by Nagy et al. (1984) require that birds be captured before and after each measurement period, a necessity that makes the measurement of time budgets for individual foraging trips impractical for many species. Here we report time budgets of Common Murres (Uria aalge), recorded using a new technique that permits measurement of activity budgets and estimation of potential foraging ranges during individual, consecutive foraging trips.

\section{METHODS}

Time budgets of Common Murres were studied at Gull Island, Witless Bay, Newfoundland $\left(47^{\circ} 16^{\prime} \mathrm{N}\right.$, $\left.52^{\circ} 46^{\prime} \mathrm{W}\right)$. Breeding birds were captured on nesting ledges with a noose-pole, and electronic activity recorders were attached at the leg and tail. Timer construction and attachment methods are described elsewhere (Cairns et al. in press). Recorders consisted of digital watches that were set at 24-h time-keeping display and wired to shut off when immersed in water. Time keeping advanced only when the devices were out of water. The recorder attached to the leg cumulatively recorded time not spent on or under water, and the tail recorder measured time not spent under water. Because birds at sea are either diving, flying, or on the water surface, a complete time budget for a foraging trip can be calculated if the timers are read before and after a trip. We accomplished this by reading displayed times through a telescope from a blind located about $16 \mathrm{~m}$ from the breeding ledge. Timers on the tail were difficult to read at the site used during incubation, so we shifted observations of birds rearing chicks to another site where readings of both timers could be made more easily.

Leg and tail timers weighed approximately $12.5 \mathrm{~g}$ each, and together added about $2.5 \%$ to body mass. We tested the accuracy of timer function by observing captive birds fitted with timers, and by immersing timers in salt water before timers were attached and after they were recovered from birds. Time keeping stopped immediately upon immersion, and resumed 1-3 s after the instrument was removed from 
TABLE 1. Time budgets of incubating and chick-rearing Common Murres.

\begin{tabular}{|c|c|c|c|c|c|}
\hline & \multicolumn{5}{|c|}{ Time allocation } \\
\hline & $\begin{array}{l}\text { On or under } \\
\text { water }\end{array}$ & Diving & Surface & Flying & Colony \\
\hline \multicolumn{6}{|c|}{ Percentage of trip time (all trips) ${ }^{a}$} \\
\hline \multicolumn{6}{|c|}{ Incubation } \\
\hline$\%$ & 90.2 & 5.1 & 83.3 & 9.8 & - \\
\hline No. trips measured & 16 & 1 & 1 & 16 & - \\
\hline Total min measured & 14,310 & 1,954 & 1,954 & 14,310 & - \\
\hline \multicolumn{6}{|l|}{ Chick rearing } \\
\hline$\%$ & 90.4 & 13.6 & 79.0 & 9.6 & - \\
\hline No. trips measured & 48 & 38 & 30 & 48 & - \\
\hline Total min measured & 12,306 & 12,618 & 9,207 & 12,306 & - \\
\hline \multicolumn{6}{|c|}{ Percentage of trip time (daytime trips) ${ }^{\mathrm{a}}$} \\
\hline \multicolumn{6}{|l|}{ Incubation } \\
\hline$\%$ & 88.2 & - & - & 11.8 & - \\
\hline No. trips measured & 7 & - & - & 7 & - \\
\hline Total min measured & 806 & - & - & 806 & - \\
\hline \multicolumn{6}{|l|}{ Chick rearing } \\
\hline$\%$ & 89.5 & 16.8 & 75.3 & 10.5 & - \\
\hline No. trips measured & 40 & 30 & 24 & 40 & - \\
\hline Total min measured & 6,430 & 5,062 & 4,401 & 6,430 & - \\
\hline \multicolumn{6}{|c|}{ Percentage of total time (from all trips) } \\
\hline Incubation (\%) & 39.8 & 2.3 & 37.5 & 4.3 & $55.9^{c}$ \\
\hline Chick rearing $(\%)$ & 44.2 & 6.6 & 37.6 & 4.7 & $51.1^{\mathrm{d}}$ \\
\hline
\end{tabular}

a Diving time + surface time does not equal water time because times are calculated from different trips.

b Surface time adjusted so that diving time + surface time $=$ water time.

' From 22,661 bird-min of observation.

d From 38,694 bird-min of observation.

water. Time keeping did not stop in heavy rain or when the instrument was placed under a shower nozzle set at maximum flow. Timers were not turned off by contact with wet feathers of resting birds; this was verified by readings taken at the beginning and end of periods spent on the breeding ledge.

\section{RESULTS}

Data were obtained on 72 trips made by 11 Common Murres in June and July 1985. Because birds probably do not forage on most brief trips, we considered only trips longer than 10 min. All birds engaged in normal incubation or chick-rearing activities during the study. During both incubation and chick rearing, about $90 \%$ of murres' time away from the colony was spent on or under water and about $10 \%$ was spent flying (Table 1 ). The single record of diving time during incubation was $5.1 \%$ of time away from the colony. Birds rearing chicks dove $13.6 \%$ of the time during 38 trips. Proportions of diving and flying time were similar between trips that included nighttime periods, and trips that were completed in daytime (Table 1).

Because pursuit-diving birds must surface to breathe, interdive interval is an essential component of foraging behavior. Using a divepause ratio of 3.6 (Dewar 1924) and dive time amounting to $13.6 \%$ of foraging trips during chick rearing (Table 1), total active foraging time during this period was estimated to be $17.4 \%$ of trip time. The sum of active foraging and flight time was $27 \%$, which represents the time birds spent in energetically expensive activities directly related to food gathering. The remainder of the time $(73 \%)$ was spent resting or swimming on the surface. During trips completed in daytime, murres spent $68 \%$ of their time swimming or resting on the surface and $32 \%$ of their time actively foraging or flying.

Measured against total time, including time at the colony, incubating murres spent $39.8 \%$ of their time on or under water and $4.3 \%$ flying. Murres rearing chicks spent $44.2 \%$ of time on or under water, $4.7 \%$ flying, and $6.6 \%$ diving. 


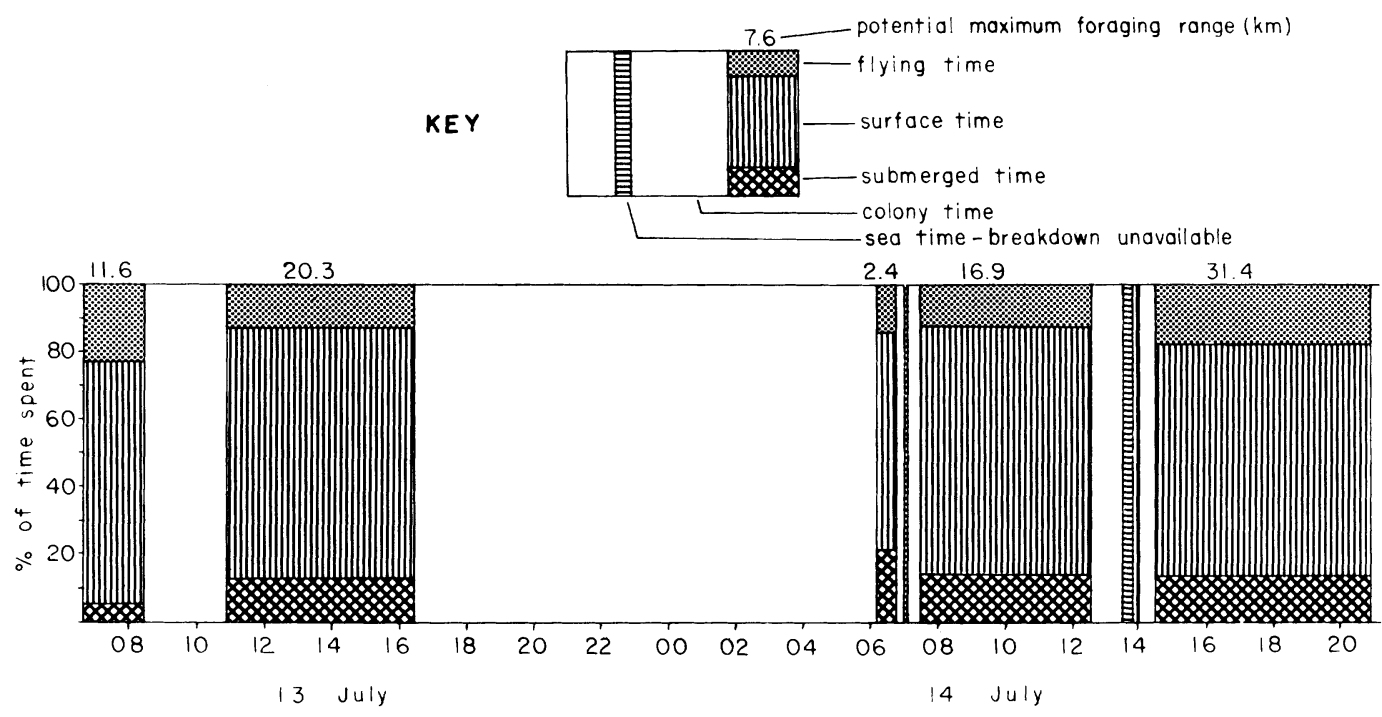

Fig. 1. Time budget of a chick-rearing Common Murre on 13 and 14 July 1985. Values on horizontal axis are hour of day. The proportions of total trip time spent flying, on the surface, and diving are indicated by the height of the hatching type that represents each activity.

Figure 1 illustrates time allocation on consecutive trips by an individual bird. Figure 2 relates diving and flight time to total trip time. The proportion of time birds spent diving decreased with trip time (Fig. 2A). Some short trips consisted entirely of flight, but in general the proportion of the foraging trip devoted to flight did not vary with trip duration (Fig. 2B, C). Except for short trips, birds never spent more than about $40 \%$ of trip time either diving or flying (Figs. 1 and 2).

Common Murres seen in flight during the breeding season off the east coast of Newfoundland are nearly always headed directly toward or away from colonies (pers. obs., D. C. Schneider pers. comm.). Using a flight speed of $58 \mathrm{~km} / \mathrm{h}$ (Tuck 1961), we calculated potential range of foraging trips for which flight time was known. Median potential foraging range was $37.8 \mathrm{~km}$ for 16 trips during incubation and $5.4 \mathrm{~km}$ for 48 trips during chick rearing $(P=$ 0.006 , Mann-Whitney-Wilcoxon test). The frequency distribution of potential ranges was concave for both incubation and chick-rearing periods (Fig. 3), and in both periods the modal range was less than $10 \mathrm{~km}$. Maximum potential ranges were $123 \mathrm{~km}$ during incubation and 80 $\mathrm{km}$ during chick rearing.

\section{Discussion}

Interpretation of data from instruments attached to animals assumes that the devices do not substantially alter behavior. In the present study, biases could result from (1) trauma due to capture and handling, (2) loss of flight efficiency due to the mass of the instruments, and (3) loss of diving efficiency due to interruption of water flow by the instruments. Our data are unlikely to be biased by capture-related stress, because we excluded the absence period following capture from our analysis, and because all birds were incubating or rearing chicks in apparently normal fashion during the observation period. Timers attached to murres increased their mass by $25 \mathrm{~g}$. Estimates of the costs of transporting instrument packages (Caccamise and Hedin 1985) suggest that timers used in this study increased flight cost to murres by $6.1 \%$ and required consumption of $11 \%$ of available surplus power.

The murres' timers had a frontal area of 7.1 $\mathrm{cm}^{2}$, or $7.9 \%$ of the bird's maximum cross-sectional area. Wilson et al. (1986) found that devices attached to Jackass Penguins (Spheniscus demersus) reduced mean swimming speed during foraging trips, and they presented a for- 


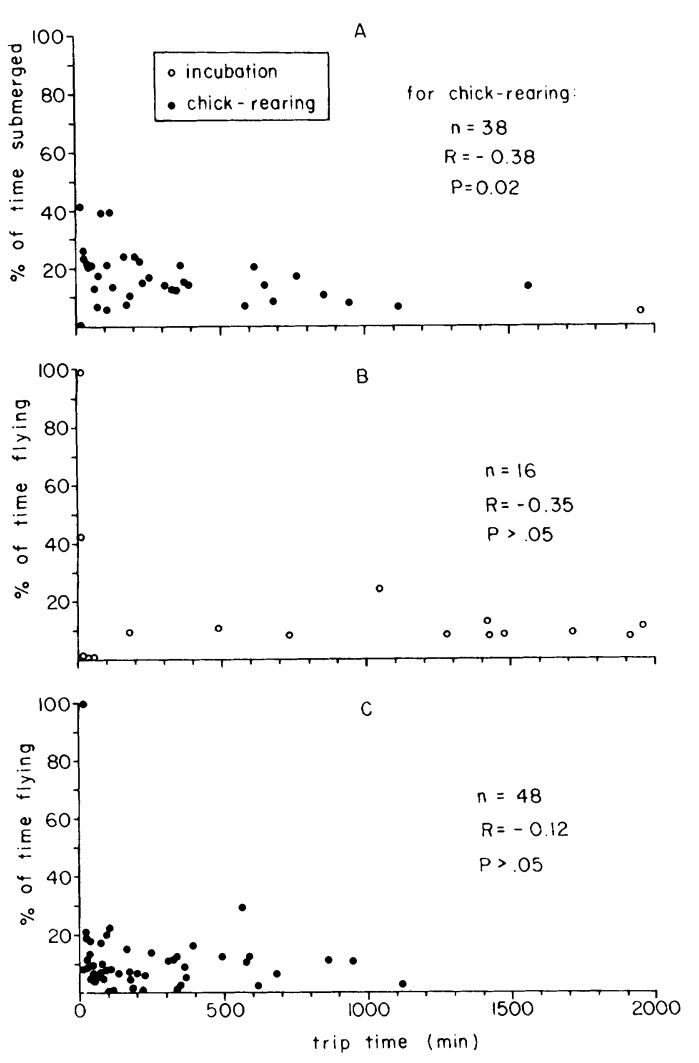

Fig. 2. Percentage of time Common Murres spent diving and flying when absent from the colony vs. duration of absence period. Percentages of (A) diving time during incubation and chick rearing, (B) flying time during incubation, and $(C)$ flying time during chick rearing are shown. Dots represent individual absence periods. Correlations are Spearman rank correlations, with two-tailed tests.

mula that allowed correction for this bias. Instruments carried by murres were located at the posterior end of the body, a position where hydrodynamic drag may be lower than the midbody attachment used by Wilson et al. (1986). Hydrodynamic drag may also impair maneuverability during underwater pursuit. However, captive murres fitted with timers and observed in a large aquarium appeared to be as agile and adept at swimming and diving as murres without timers.

The effect of aerodynamic and hydrodynamic inefficiencies because of attached instruments is difficult to evaluate in seabirds, because it is not possible to measure activity

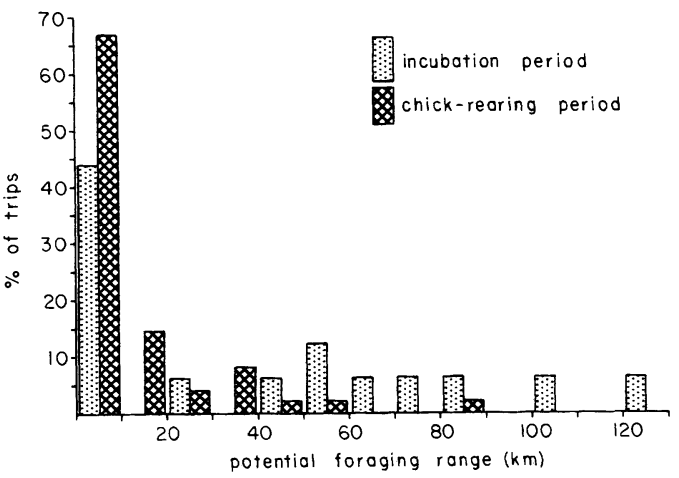

Fig. 3. Frequency distribution of potential foraging range of Common Murres, from 16 trips during incubation and 48 trips during chick rearing.

budgets without instruments. Labeled-water measurements of energy expenditure by birds with and without attachments may resolve this question. Wilson et al. (1986) assumed that the relation between mean swimming speed and instrument cross-sectional area was linear for instruments smaller than those for which they had data. It is uncertain whether this assumption is valid, because birds may compensate for small instrument loads by adjusting time allocations or by increasing effort during swimming and flying. We consider that the overall effects of our instruments on murre time budgets are probably small and of the same order as error contained in other studies that involve attachment of devices to animals.

Common Murres often preen and bathe on the water. Because of the lag time between removal from water and resumption of time keeping, it is unlikely that brief exits of a bird's leg from the water during preening would affect significantly operation of the timer and calculation of total water time and flight time. However, splashing and dipping could shut off tail timers during part of a preening bout, and result in overestimated dive times and underestimated surface times.

The low reproductive rates of seabirds generally are attributed to limitations in the ability of adults to deliver food to offspring (Lack 1968, Ricklefs 1983). However, empirical and theoretical studies suggest many large endotherms spend relatively little time gathering food (Herbers 1981, Walsberg 1983). Our data suggest that Common Murres rearing chicks spent 
only $27 \%$ of their time flying and actively foraging. Unless time allocated to rapid locomotion is constrained by the need to digest food (Diamond et al. 1986) or limits to daily energy expenditure (Drent and Daan 1980), murres at Gull Island in 1985 may have been capable of delivering more food to chicks than they did. This possibility is consistent with recent suggestions that chick provisioning by seabirds is regulated by chick demands rather than by food availability (Ricklefs et al. 1985, Shea and Ricklefs 1985).

Data on attendance patterns at the colony and chick growth rates have been used to assess prey availability for many seabirds (e.g. Gaston and Nettleship 1982, Gaston et al. 1983, Verspoor et al. in press). These parameters, however, will show poor correspondence to food availability when prey abundance is medium or high if birds respond to declining prey availability by devoting more of their time away from the colony to foraging. Brown and Nettleship (1980) suggested that Atlantic Puffin (Fratercula arctica) fledging weights at Witless Bay vary with abundance of capelin (Mallotus villosus), the primary food of alcids in the area. If Common Murres have excess time available that could be used for chick provisioning, such measurements may be relatively insensitive to changes in capelin abundance. More reliable information on prey availability might be obtained by directly measuring time allocated to food procurement by means of activity timers. The use of seabird activity budgets to provide indices of prey availability and abundance may have wide applicability, including assessment of fluctuations in commercially exploited fish stocks that are difficult to estimate by conventional means (e.g. Anon. 1981).

Chick-rearing Common Murres allocated a smaller portion of their time at sea to rapid locomotion than did other seabird species for which time budgets away from the colony are available. Nagy et al. (1984) reported that Jackass Penguins allocated $45 \%$ of trip time to traveling and diving, and Trivelpiece et al. (1986) found that Gentoo and Chinstrap penguins (Pygoscelis papua and P. antarctica) spent $97 \%$ of trip time traveling or foraging. However, penguins may spend most of their resting time on land, unlike murres in which most rest time is spent on the water. Breeding Sooty Terns (Sterna fuscata) and Gray-headed Albatrosses (Diomedea chrysostoma) spent $100 \%$ and $74 \%$ of their time away from the colony in flight, respectively (Flint and Nagy 1984, Prince and Francis 1984). Because travel costs are low in these species (Pennycuick 1982, Flint and Nagy 1984), the terns' and albatrosses' high percentage of flight time does not mean these birds are working harder to obtain food than are murres or penguins.

There are few published data on Common Murre foraging ranges. Murres have been found to feed at distances ranging from 8 to 60 $\mathrm{km}$ from the colony (Schneider and Hunt 1984, Bradstreet and Brown 1985). Absence bouts are much longer during incubation than during chick rearing (Verspoor et al. in press), and the greater foraging range during incubation corresponds to the longer trip times then.

Murres from the Witless Bay colonies form foraging aggregations over large capelin schools within $5 \mathrm{~km}$ of their breeding sites, but feeding birds also are seen in large numbers along the Newfoundland coastline within $15 \mathrm{~km}$ of the colonies (Piatt et al. 1984, Piatt pers. comm., pers. obs.). Some murres from Witless Bay also feed at an offshore ridge about $80 \mathrm{~km}$ southeast of the colonies, where fish-carrying birds have been seen flying in the direction of Witless Bay (D. C. Schneider unpubl. data). The distribution of potential ranges of foraging trips (Fig. 3 ) indicates that waters close to the colony are the most frequent destination of feeding birds. This is particularly true during chick rearing, when only one third of feeding trips could have exceeded $10 \mathrm{~km}$ from the colony.

Owing to the difficulty of directly measuring foraging ranges, maximum foraging ranges have been calculated for some seabirds on the basis of flight speed and time absent from the breeding site (e.g. Pearson 1968, Furness and Todd 1984, Furness and Barrett 1985). Our data on flight times during foraging trips suggest that this approach would result in a 10 -fold overestimate of murre foraging ranges. $\mathrm{Ab}$ sence times may nevertheless indicate relative foraging range in intercolony comparisons, particularly in gliding species that spend most of their time in flight. The use of recording devices that allow collection of time-budget data on large numbers of consecutive foraging trips promises insight into many poorly understood areas of seabird ecology, including energy requirements of breeding, geographic patterns of resource use, and the relation of food-gathering ability to life-history parameters. 


\section{ACKNOWLEDGMENTS}

We thank A. E. Burger, R. D. Elliot, N. House, and M. Simpson for collaboration and assistance in the field, and J. F. Piatt and D. C. Schneider for providing unpublished data and critical comments. S. Parent of the Aquarium de Montréal kindly arranged instrument tests on captive birds. The Newfoundland anc Labrador Wildlife Division authorized our work on Gull Island, which is part of the Witless Bay Ecological Reserve. This study was funded by a Fisheries and Oceans Canada Subvention Grant (DKC and WAM), Natural Sciences and Engineering Research Council Grant Nos. A0687 and E6828 (WAM), and the Newfoundland Institute for Cold Ocean Science and Psychology Department of Memorial University. This is report No. 115 from the Newfoundland Institute for Cold Ocean Science.

\section{LITERATURE CITED}

ANONYMOUS. 1981. Advice on pelagic stocks. Can. Atl. Fish. Sci. Adv. Comm. Advisory Document $81 / 7$.

BradstreEt, M. S. W., \& R. G. B. BRoWN. 1985. Feeding ecology of the Atlantic Alcidae. Pp. 263-318 in The Atlantic Alcidae (D. N. Nettleship and T. R. Birkhead, Eds.). London, Academic Press.

Brown, R. G. B., \& D. N. Nettleship. 1984. Capelin and seabirds in the northwest Atlantic. Pp. 184194 in Marine birds: their feeding ecology and commercial fisheries relationships (D. N. Nettleship, G. A. Sanger, and P. F. Springer, Eds.). Ottawa, Canadian Wildl. Serv.

CACCAMISE, D. F., \& R. S. HedIN. 1985. An aerodynamic basis for selecting transmitter loads in birds. Wilson Bull. 97: 306-318.

CaIRns, D. K., K. A. Bredin, V. L. Birt, \& W. A. MONTEVECCHI. In press. Electronic activity recorders for aquatic wildlife. J. Wildl. Mgmt.

DEWAR, J. M. 1924. The bird as a diver. London, Witherby.

Diamond, J. M., W. H. Karasov, D. Phan, \& F. L. CARPENTER. 1986. Digestive physiology is a determinant of foraging bout frequency in hummingbirds. Nature 320: 62-63.

DRENT, R. H., \& S. DAAN. 1980. The prudent parent: energetic adjustments in avian breeding? Ardea 68: 225-252.

Flint, E. N., \& K. A. NAGY. 1984. Flight energetics of free-living Sooty Terns. Auk 101: 288-294.

FURNESS, R. W. 1978. Energy requirements of seabird communities: a bioenergetics model. J. Anim. Ecol. 47: 39-53.

—, \& R. T. BARRETT. 1985. The food requirements and ecological relationships of a seabird community in north Norway. Ornis Scandinavica 16 : 305-313.

— \& J. COOPER. 1982. Interactions between breeding seabirds and pelagic fish populations in the southern Benguela region. Mar. Ecol. Prog. Ser. 8: 243-250.

- \& C. M. ToDD. 1984. Diets and feeding of fulmars Fulmarus glacialis during the breeding season: a comparison between St Kilda and Shetland colonies. Ibis 126: 379-387.

Gaston, A. J. 1985. Energy invested in reproduction by Thick-billed Murres (Uria lomvia). Auk 102: 447-458.

- G. Chapdelaine, \& D. G. Noble. 1983. The growth of Thick-billed Murre chicks at colonies in Hudson Strait: inter- and intra-colony variation. Can. J. Zool. 61: 2465-2475.

$\longrightarrow \rightarrow-$ \& D. N. NeTtLESHIP. 1982. Factors determining seasonal changes in attendance at colonies of the Thick-billed Murre Uria lomvia. Auk 99: 468-473.

HARRISON, C. S. 1981. Radiotelemetry of the Brown Noddy in Hawaii. J. Wildl. Mgmt. 45: 1021-1025.

HERBERS, J. M. 1981. Time resources and laziness in animals. Oecologia 49: 252-262.

LACK, D. 1968. Ecological adaptations for breeding in birds. London, Methuen.

Nagy, K. A., W. R. Siegfried, \& R. P. Wilson. 1984. Energy utilization by free-ranging Jackass Penguins, Spheniscus demersus. Ecology 65: 1648-1655.

PEARSON, T. H. 1968. The feeding biology of seabird species breeding on the Farne Islands, Northumberland. J. Anim. Ecol. 37: 521-552.

PenNycuick, C. J. 1982. The flight of petrels and albatrosses (Procellariiformes), observed in South Georgia and vicinity. Phil. Trans. Roy. Soc. London B 300: 75-106.

Piatt, J. F., D. N. NetTleship, \& W. Threlfall. 1984. Net-mortality of Common Murres and Atlantic Puffins in Newfoundland, 1951-81. Pp. 196-206 in Marine birds: their feeding ecology and commercial fisheries relationships (D. N. Nettleship, G. A. Sanger, and P. F. Springer, Eds.). Ottawa, Canadian Wildl. Serv.

Prince, P. A., \& M. D. Francis. 1984. Activity budgets of foraging Gray-headed Albatrosses. Condor 86: 297-300.

RICKLEFS, R. E. 1983. Some considerations of the reproductive energetics of pelagic seabirds. Stud. Avian. Biol. 8: 84-94.

, C. H. DAY, C. E. Huntington, \& J. B. WiLLIAMS. 1985. Variability in feeding rate and meal size of Leach's Storm-Petrel at Kent Island, New Brunswick. J. Anim. Ecol. 54: 883-898.

SCHNEIDER, D. C., \& G. L. HuNT. 1984. A comparison of seabird diets and foraging distribution around the Pribilof Islands, Alaska. Pp. 86-95 in Marine birds: their feeding ecology and commercial fisheries relationships (D. N. Nettleship, G. A. Sanger, and P. F. Springer, Eds.). Ottawa, Canadian Wildl. Serv.

SHEA, R. E., \& R. E. RiCKLEFS. 1985. An experimental 
test of the idea that food supply limits growth rate in a tropical pelagic seabird. Amer. Natur. 126: $116-122$.

$\rightarrow$ Trivelpiece, W. Z., J. L. Bengston, S. G. Trivelpiece, \& N. J. VOLKMAN. 1986. Foraging behavior of Gentoo and Chinstrap penguins as determined by new radiotelemetry techniques. Auk 103: 777781.

TuCK, L. M. 1961. The murres. Ottawa, Canadian Wildl. Serv.

VERSPOOR, E., T. R. BIRKHEAD, \& D. N. NETTLESHIP. In press. Incubation and brooding shift duration in the Common Murre, Uria aalge. Can. J. Zool.

WALSBERG, G. E. 1983. Avian ecological energetics. Pp. 161-220 in Avian biology, vol. 7 (D. S. Far- ner, J. R. King, and K. C. Parkes, Eds.). New York, Academic Press.

WANLESS, S., M. P. HARRIS, \& J. A. MORRIS. 1985. Radio-monitoring as a method for estimating time budgets of guillemots Uria aalge. Bird Study 32: 170-175.

WIENS, J. A. 1984. Modelling the energy requirements of seabird populations. Pp. 255-284 in Seabird energetics (G. C. Whittow and H. Rahn, Eds.). New York, Plenum Press.

Wilson, R. P., W. S. Grant, \& D. C. Duffy. 1986. Recording devices on free-ranging marine animals: does measurement affect foraging performance? Ecology 67: 1091-1093. 